\title{
Photochromism of Indolino-Benzopyrans Studied by NMR and UV-Visible Spectroscopy
}

\author{
S. Delbaere, ${ }^{1}$ J. Berthet, ${ }^{1}$ M. A. Salvador, ${ }^{2}$ G. Vermeersch, ${ }^{1}$ and M. M. Oliveira ${ }^{2}$ \\ ${ }^{1}$ CNRS UMR 8009, Laboratoire de Physique, Faculté de Pharmacie, Université de Lille 2, 59006 Lille Cedex, France \\ ${ }^{2}$ Centro de Química, Universidade de Trás-os-Montes e Alto Douro, 5000-911 Vila Real, Portugal
}

Received 20 February 2006; Accepted 20 February 2006

The synthesis of photochromic 3,3-di(4'-fluorophenyl)-3H-benzopyrans fused to an indole moiety is described. The structures of photomerocyanines elucidated by NMR spectroscopy and spectrokinetic data ( $\lambda_{\max }$ of colored form, colorability, and rate constant of bleaching) obtained by UV-visible spectroscopy are reported.

Copyright (c) 2006 S. Delbaere et al. This is an open access article distributed under the Creative Commons Attribution License, which permits unrestricted use, distribution, and reproduction in any medium, provided the original work is properly cited.

\section{INTRODUCTION}

Photochromism of benzopyrans can be defined as the photoinduced bond cleavage leading to equilibrium between different photoisomers $[1,2]$. Such structures commonly named open and colored forms have a distinct absorption spectrum generally in the visible range and return to the initial closed form via thermal or photochemical pathways. These properties find applications in many industrial fields, the most known being in ophthalmic glasses [3]. In the course of developing photochromic performances, research of structures giving rise to high colorability, fast thermal or photochemical bleaching, and low degradation is the subject of many investigations. Indeed, the photochromic parameters depend significantly not only on the relative positions of the heteroannellation on the benzopyrans but also on the introduction of electron donating and withdrawing groups.

Recent NMR studies on closed and colorless 3,3-diphenyl-3H-naphthopyrans underlined the formation of two isomers of open colored form, namely, the photomerocyanines TC and TT [4]. Coupling NMR spectroscopy and UV-visible studies makes it possible to envisage a better understanding of mechanism involved in the photochromic reaction [5-8]. Some of us have recently reported the synthesis and properties of new benzopyrans containing an indole moiety. According to the nature of substituent on the nitrogen atom (hydrogen or methyl), they presented after irradiation different absorption spectra and different rate constants of bleaching [9]. Then, we decided to understand the origin of this phenomenon using two spectroscopic approaches: UV-visible and nuclear magnetic resonance. To do that, fluorinated $2 \mathrm{H}$-benzopyrans have been synthesized to use this nucleus as molecular probe in ${ }^{19} \mathrm{~F}$ NMR spectroscopy, in addition to ${ }^{1} \mathrm{H}$ NMR.

In the present paper, we report the synthesis of 3,3diphenyl-3H-benzopyrans substituted by fluorine atoms in para position of both phenyl groups and annellated in 5, 6 position to an indole moiety (Scheme 1). The structural identifications of photoproducts and thermodynamic parameters obtained by NMR spectroscopy and spectrokinetic properties ( $\lambda_{\max }$ of colored form, colorability, and rate constant of bleaching) obtained by UV-visible spectroscopy are here compared and discussed.

\section{EXPERIMENTAL DETAILS}

NMR spectra of CF-1 $\left(5.10^{-3} \mathrm{M}\right.$ in toluene- $\mathrm{d}_{8}$ and acetone$\left.\mathrm{d}_{6}\right)$ and CF-3 $\left(5.10^{-3} \mathrm{M}\right.$ in toluene- $\left.\mathrm{d}_{8}\right)$ were acquired using Bruker DPX300 NMR spectrometer operating at $300 \mathrm{MHz}$ $\left({ }^{1} \mathrm{H}\right), 75 \mathrm{MHz}\left({ }^{13} \mathrm{C}\right)$, and $282 \mathrm{MHz}\left({ }^{19} \mathrm{~F}\right)$. UV irradiation of the samples in the NMR tube was performed in a home-built apparatus with a 1000 Watt $\mathrm{Xe}-\mathrm{Hg}$ lamp, equipped with filter Schott 011FG09 $\left(259<\lambda<388 \mathrm{~nm}\right.$ with $\lambda_{\max }=330 \mathrm{~nm}$ and $T=79 \%)$. During irradiation, the sample was kept spinning for homogenization and the temperature was controlled with a variable temperature unit. After irradiation had been stopped, the tube was transferred into the NMR probe, also thermoregulated, of the spectrometer.

For UV-visible spectroscopy, irradiation experiments were made using a CARY 50 Varian spectrometer coupled to a $150 \mathrm{~W}$ ozone-free Xenon lamp (6255 Oriel Instruments). 


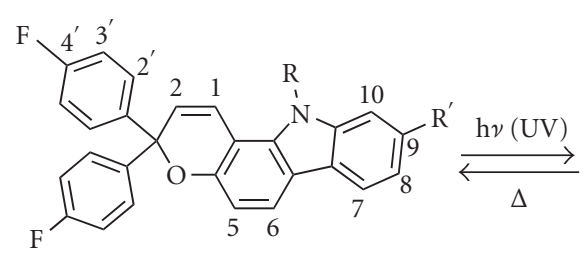

$\mathrm{R}=\mathrm{H}, \mathrm{R}^{\prime}=\mathrm{H}: \quad \mathrm{CF}-1$

$\mathrm{R}=\mathrm{H}, \mathrm{R}^{\prime}=\mathrm{Br}: \quad \mathrm{CF}-2$

$\mathrm{R}=\mathrm{CH}_{3}, \mathrm{R}^{\prime}=\mathrm{H}: \quad \mathrm{CF}-3$

$\mathrm{R}=\mathrm{CH}_{3}, \mathrm{R}^{\prime}=\mathrm{Br}: \quad \mathrm{CF}-4$<smiles>[R]c1ccc2c3c(n([R])c2c1)/C(=C/C=C(c1ccc(F)cc1)c1ccc(F)cc1)C(=O)C=C3</smiles>

TC

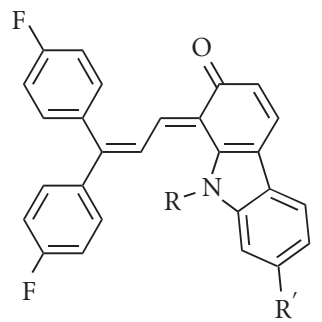

TT

Scheme 1: Photochromic equilibrium.

The light from the UV lamp was filtered using a water filter (61945 Oriel Instruments) and then carried to the spectrophotometer holder at the right angle to the monitoring beam using an optical fiber system (77654 Oriel Instruments). A light flux of $40 \mathrm{Wm}^{-2}$, measured with a Goldilux photometer with UV-A probe, was used. A thermostated $\left(20^{\circ} \mathrm{C}\right) 10 \mathrm{~mm}$ quartz cell, containing the sample solution $(3.5 \mathrm{ml})$, equipped with magnetic stirring, was used. In a preliminary experiment, the visible absorption spectrum of the closed form and the $\lambda_{\max }$ of the open form were determined. In a second experiment, the absorbance at photostationary equilibrium, $A_{\mathrm{eq}}$, was measured at $\lambda_{\max }$ and then the decrease in the absorbance versus time was monitored. The rate constants were calculated using a multiexponential model.

\section{RESULTS}

\subsection{Synthesis}

The synthesis of 1,1-di(4'-fluorophenyl)-2-propyn-1-ol (1) has been reported [10]. Synthesis of 3,3-di(4'-fluorophenyl) prop-2-enal (2) has been reported [11] but the reaction conditions have been here changed because, without the presence of a solvent (1,4-dioxane) and with concentrated sulfuric acid, the final product was not achieved (Scheme 2). 2-bromo-7-hydroxycarbazole was prepared in 31\% overall yield by crossed Ullmann reaction from commercially available compounds followed by treatment with triethylphosphite and demethylation [9]. The heteroannellation was obtained by the organotitanium-mediated condensation of 2-bromo-7-hydroxycarbazole with aldehyde (2), leading to
C-alkylation in ortho-position that through a subsequent electrocyclization yields the new benzopyrans CF-1 and CF2 in a $22 \%$ and $51 \%$ yield, respectively (Scheme 2) [12]. The benzopyrans CF-3 (54\%) and CF-4 (42\%) were obtained by methylation by phase transfer catalysis with benzyl triethyl ammonium chloride (BTEAC) from CF-1 and CF-2, respectively. All the known compounds showed melting points and spectral characteristics in accordance with literature values [9].

(i) 3,3-di (4', 4'-fluorophenyl)-3H, 11H-pyrane[3,2-a]carbazole (CF-1) (22\%); white solid; mp 206.5-207.2 ${ }^{\circ} \mathrm{C}$; UV $\lambda_{\max }$ (toluene)/nm (closed form): 325, 339, and $353\left(\varepsilon / \mathrm{dm}^{3} \mathrm{~mol}^{-1} \mathrm{~cm}^{-1} 6400,7300,7850\right)$; IR $\left(v_{\max } / \mathrm{cm}^{-1}, \mathrm{KBr}\right.$ pellets $): 3432(\mathrm{NH}), 3043,1635$, $1600,1502,1455,1211,1153,1078,823,757,570 ;{ }^{1} \mathrm{H}$ and ${ }^{19} \mathrm{~F}$ NMR $\left(300 \mathrm{MHz}\right.$, toluene- $\left.\mathrm{d}_{8}\right): \delta 5.82(1 \mathrm{H}, \mathrm{d}$, $J=9.6 \mathrm{~Hz}, 2-\mathrm{H}), 6.40(1 \mathrm{H}, \mathrm{d}, J=9.6 \mathrm{~Hz}, 1-\mathrm{H})$, $6.76\left(4 \mathrm{H}, \mathrm{dd}, J_{3^{\prime}-2^{\prime}}=8.7 \mathrm{~Hz}\right.$ and $J_{3^{\prime}-\mathrm{F}}=8.5 \mathrm{~Hz}, 3^{\prime}-$ $\mathrm{H}), 6.80(1 \mathrm{H}$, br s, N-H), $6.83(1 \mathrm{H}, \mathrm{d} J=8.5 \mathrm{~Hz}$, 5-H), $7.03(1 \mathrm{H}, \mathrm{dd} J=1.2$ and $7.9 \mathrm{~Hz}, 10-\mathrm{H}), 7.14$ $(1 \mathrm{H}$, ddd $J=1.2$ and $7.9 \mathrm{~Hz}, 8-\mathrm{H}), 7.28(1 \mathrm{H}$, ddd $J=1.2$ and $7.9 \mathrm{~Hz}, 9-\mathrm{H}), 7.31\left(4 \mathrm{H},{\mathrm{dd} J 2^{\prime}-3^{\prime}}^{\prime}=8.7 \mathrm{~Hz}\right.$ and $\left.J_{2^{\prime}-\mathrm{F}}=5.3 \mathrm{~Hz}, 2^{\prime}-\mathrm{H}\right), 7.56(1 \mathrm{H}$, dd $J=8.5 \mathrm{~Hz}, 6-$ $\mathrm{H}), 7.75(1 \mathrm{H}, \mathrm{dd} J=1.0$ and $7.9 \mathrm{~Hz}, 7-\mathrm{H}) .{ }^{13} \mathrm{C}$ NMR $\left(75.47 \mathrm{MHz}\right.$, toluene- $\left.\mathrm{d}_{8}\right): 82.0(\mathrm{C}-3), 105.0(\mathrm{C}-11 \mathrm{~b})$, $109.9(\mathrm{C}-5), 110.8(\mathrm{C}-10), 115.2\left(\mathrm{C}-3^{\prime}, J_{3^{\prime}-\mathrm{F}}=21 \mathrm{~Hz}\right)$, 118.8 (C-6a), 119.2 (C-1), 119.9 (C-7), 120.2 (C-8); 124.0 (C-6b), 125.0 (C-9), 127.2 (C-2), 129.4 (C-2', $\left.J_{2^{\prime}-\mathrm{F}}=8 \mathrm{~Hz}\right), 136.9$ (C-11a), $140.1(\mathrm{C}-10 \mathrm{a}), 141.2(\mathrm{C}-$ $\left.1^{\prime}, J_{1^{\prime}-\mathrm{F}}=3.6 \mathrm{~Hz}\right), 162.5\left(\mathrm{C}-4^{\prime}, J_{4^{\prime}-\mathrm{F}}=246 \mathrm{~Hz}\right) . \mathrm{MS}$ $(\mathrm{EI}, 70 \mathrm{eV}): \mathrm{m} / \mathrm{z}(\%): 409\left(\mathrm{M}^{+\bullet}, 100\right), 314(72), 285$ 

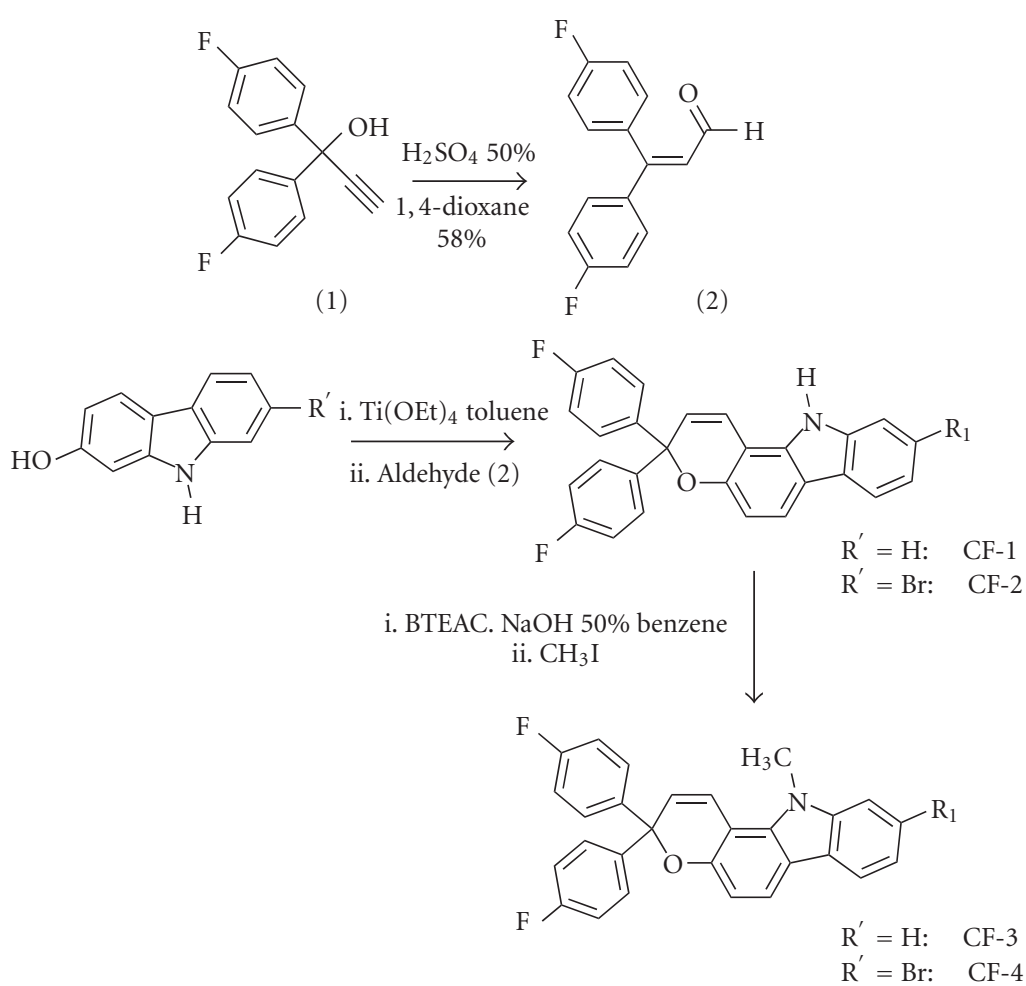

Scheme 2: General synthetic procedures for compound 2 and benzopyrans CF- 1 to CF- 4 .

(9), 205 (12), 157 (7). Exact mass for $\mathrm{C}_{27} \mathrm{H}_{17} \mathrm{~F}_{2} \mathrm{NO}$ : 409.12782. Found: 409.1278.

(ii) 9-bromo-3,3-di (4', 4"'-fluorophenyl)-3H, 11H-pyrane[3,2-a]carbazole (CF-2) (51\%), white solid mp 237$238^{\circ} \mathrm{C}$, UV $\lambda_{\max }$ (toluene)/nm (closed form): 327, 329, 338, and $353\left(\varepsilon / \mathrm{dm}^{3} \mathrm{~mol}^{-1} \mathrm{~cm}^{-1} 8550,8560,8580\right.$, 7980); IR ( $v_{\max } / \mathrm{cm}^{-1}, \mathrm{KBr}$ pellets): $3419(\mathrm{NH}), 1643$, 1606, 1506, 1222, 1083, 831, 802; ${ }^{1} \mathrm{H}$ and ${ }^{19} \mathrm{~F}$ NMR $\left(300 \mathrm{MHz}\right.$, toluene- $\left.\mathrm{d}_{8}\right): \delta 5.81(1 \mathrm{H}, \mathrm{d} J=9.9 \mathrm{~Hz}, 2-$ $\mathrm{H}), 6.33(1 \mathrm{H}, \mathrm{d} J=9.9 \mathrm{~Hz}, 1-\mathrm{H}), 6.63(1 \mathrm{H}$, br s, $\mathrm{N}-\mathrm{H}), 6.76\left(4 \mathrm{H}\right.$, dd $J_{3^{\prime}-2^{\prime}}=9.0 \mathrm{~Hz}$ and $J_{3^{\prime}-\mathrm{F}}=8.6 \mathrm{~Hz}$, $\left.3^{\prime}-\mathrm{H}\right), 6.80(1 \mathrm{H}, \mathrm{d} J=8.5 \mathrm{~Hz}, 5-\mathrm{H}), 7.15(1 \mathrm{H}, \mathrm{d} J=$ $1.7 \mathrm{~Hz}, 10-\mathrm{H}), 7.22(1 \mathrm{H}$, dd $J=1.7$ and $8.3 \mathrm{~Hz}, 8-\mathrm{H})$, $7.29\left(4 \mathrm{H}\right.$, dd $J_{2^{\prime}-3^{\prime}}=9.0 \mathrm{~Hz}$ and $\left.J_{2^{\prime}-\mathrm{F}}=5.4 \mathrm{~Hz}, 2^{\prime}-\mathrm{H}\right)$, $7.37(1 \mathrm{H}, \mathrm{d} J=8.3 \mathrm{~Hz}, 7-\mathrm{H}), 7.43(1 \mathrm{H}, \mathrm{d} J=8.5 \mathrm{~Hz}$, 6-H). ${ }^{13} \mathrm{C}$ NMR (75.47 MHz, toluene- $\left.\mathrm{d}_{8}\right): 81.9$ (C-3), 105.2 (C-11b), 110.4 (C-5), 114.1 (C-10), 115.2 (C$\left.3^{\prime}, J_{3^{\prime}-\mathrm{F}} 21,1 \mathrm{~Hz}\right), 118.0$ (C-6a), 118.3 (C-Br) 118.8 (C-1), 120.9 (C-7), 121.6 (C-6), 122.9 (C-6b), 123.3 (C-8), 127.9 (C-2), $129.2\left(\mathrm{C}-2^{\prime}, J_{2^{\prime}-\mathrm{F}} 8.2 \mathrm{~Hz}\right), 136.7$ (C-11a), 140.5 (C-10a), 140.7 (C-1'), 151.7 (C-4a), $163.0\left(\mathrm{C}-4^{\prime}, J_{4^{\prime}-\mathrm{F}} 246 \mathrm{~Hz}\right)$. MS (EI, $\left.70 \mathrm{eV}\right): \mathrm{m} / \mathrm{z}(\%): 489$ $\left({ }^{81} \mathrm{BrM}^{+\bullet}, 100\right), 487\left({ }^{79} \mathrm{BrM}^{+\bullet}, 98\right), 408$ (11), 395 (16), 394 (63), 392 (64). Exact mass for $\mathrm{C}_{27} \mathrm{H}_{16} \mathrm{BrF}_{2} \mathrm{NO}$ : 487.03833. Found: 487.03831.

(iii) 3,3-di (4', 4' -fluorophenyl)-3 H, 11H-11-methyl-pyrane 3,2 -a]carbazole (CF-3) (54\%), white solid, $\mathrm{mp}$ 214-215 ${ }^{\circ} \mathrm{C}$, UV $\lambda_{\max }$ (toluene)/nm (closed form): 345 , $360\left(\varepsilon / \mathrm{dm}^{3} \mathrm{~mol}^{-1} \mathrm{~cm}^{-1} 8110,9820\right)$; IR $\left(v_{\max } / \mathrm{cm}^{-1}\right.$,
KBr pellets): $1502,1211,1155,1029,827,738 ;{ }^{1} \mathrm{H}$ and ${ }^{19} \mathrm{~F}$ NMR (300 MHz, toluene- $\left.\mathrm{d}_{8}\right): \delta 3.20(3 \mathrm{H}, \mathrm{s}, \mathrm{NMe})$, $5.84(1 \mathrm{H}, \mathrm{d} J=9.8 \mathrm{~Hz}, 2-\mathrm{H}), 6.81\left(4 \mathrm{H}\right.$, dd $J_{3^{\prime}-2^{\prime}}=$ $8.8 \mathrm{~Hz}$ and $\left.J_{3^{\prime}-\mathrm{F}}=8.6 \mathrm{~Hz}, 3^{\prime}-\mathrm{H}\right), 6.94(1 \mathrm{H}, \mathrm{dd} J=0.7$ and $8.3 \mathrm{~Hz}, 10-\mathrm{H}), 6.94(1 \mathrm{H}, \mathrm{d} J=8.3 \mathrm{~Hz}, 5-\mathrm{H}), 7.02$ $(1 \mathrm{H}, \mathrm{d} J=9.8 \mathrm{~Hz}, 1-\mathrm{H}), 7.19(1 \mathrm{H}$, ddd $J=0.7$ and $7.8 \mathrm{~Hz}, 8-\mathrm{H}), 7.33(1 \mathrm{H}$, ddd $J=1.1$ and $8.3 \mathrm{~Hz}, 9-\mathrm{H})$, $7.39\left(4 \mathrm{H}, \mathrm{dd}_{2^{\prime}-3^{\prime}}=8.8 \mathrm{~Hz}\right.$ and $\left.J_{2^{\prime}-\mathrm{F}}=5.3 \mathrm{~Hz}, 2^{\prime}-\mathrm{H}\right)$, $7.69(1 \mathrm{H}, \mathrm{d} J=8.3,6-\mathrm{H}), 7.82(1 \mathrm{H}$, dd $J=1.1$ and $7.8 \mathrm{~Hz}, 7-\mathrm{H}) .{ }^{13} \mathrm{C}$ NMR $\left(75.47 \mathrm{MHz}\right.$, toluene- $\left.\mathrm{d}_{8}\right): 31.9$ (NMe), 81.6 (C-3), 106.7 (C-11b), 108.6 (C-6b), 109.4 $(\mathrm{C}-10), 115.3\left(\mathrm{C}-3^{\prime}, J_{3^{\prime}-\mathrm{F}}=21 \mathrm{~Hz}\right), 119.8(\mathrm{C}-7), 120.0$ (C-8), 120.9 (C-1), 121.8 (C-6), 123.5 (C-6a), 125.0 (C-9), $126.8(\mathrm{C}-2), 129.4\left(\mathrm{C}-2^{\prime}, J_{2^{\prime}-\mathrm{F}}=8 \mathrm{~Hz}\right), 138.0$ (C-11a), $141.2\left(\mathrm{C}-1^{\prime}, J_{1^{\prime}-\mathrm{F}}=3.6 \mathrm{~Hz}\right), 142.1$ (C-10a), $152.3(\mathrm{C}-4 \mathrm{a}), 162.7\left(\mathrm{C}-4^{\prime}, J_{4^{\prime}-\mathrm{F}}=246 \mathrm{~Hz}\right)$. MS (EI, $70 \mathrm{eV}): \mathrm{m} / \mathrm{z}(\%): 423\left(\mathrm{M}^{+}, 100\right), 341$ (14), 328 (57), 314 (6), 252 (8) 201 (8), 105 (7), 92 (9), 77 (7). Exact mass for $\mathrm{C}_{28} \mathrm{H}_{19} \mathrm{~F}_{2} \mathrm{NO}: 423.14347$. Found: 423.1435 .

(iv) 9-bromo-3,3-di (4', $4^{\prime \prime}$-fluorophenyl)-3H, 11H-11-methyl-pyrane [3,2-a] carbazole (CF-4) (42\%), white solid, $\mathrm{mp} 199-200^{\circ} \mathrm{C}$, UV $\lambda_{\max }$ (toluene)/nm (closed form): 332, 346, and $362\left(\varepsilon / \mathrm{dm}^{3} \mathrm{~mol}^{-1} \mathrm{~cm}^{-1}\right.$ 6990, 7180, 7970); IR ( $v_{\max } / \mathrm{cm}^{-1}, \mathrm{KBr}$ pellets): 1602, 1583, 1504, 1222, 1155, 1027, 833; ${ }^{1} \mathrm{H}$ and ${ }^{19} \mathrm{~F}$ NMR $(300 \mathrm{MHz}$, toluene- $\left.\mathrm{d}_{8}\right): \delta 2.96(3 \mathrm{H}, \mathrm{s}, \mathrm{NMe}), 5.78(1 \mathrm{H}, \mathrm{d} J=$ $9.9 \mathrm{~Hz}, 2-\mathrm{H}), 6.77\left(4 \mathrm{H}, \mathrm{dd} J_{3^{\prime}-2^{\prime}}=9.0 \mathrm{~Hz}\right.$ and $J_{3^{\prime}-\mathrm{F}}=$ $\left.8.8 \mathrm{~Hz}, 3^{\prime}-\mathrm{H}\right), 6.86(1 \mathrm{H}, \mathrm{d} J=8.3 \mathrm{~Hz}, 5-\mathrm{H}), 6.88$ $(1 \mathrm{H}, \mathrm{d} J=9.9 \mathrm{~Hz}, 1-\mathrm{H}), 7.12(1 \mathrm{H}, \mathrm{d} J=1.7$ 
${ }^{1} \mathrm{H}$ NMR

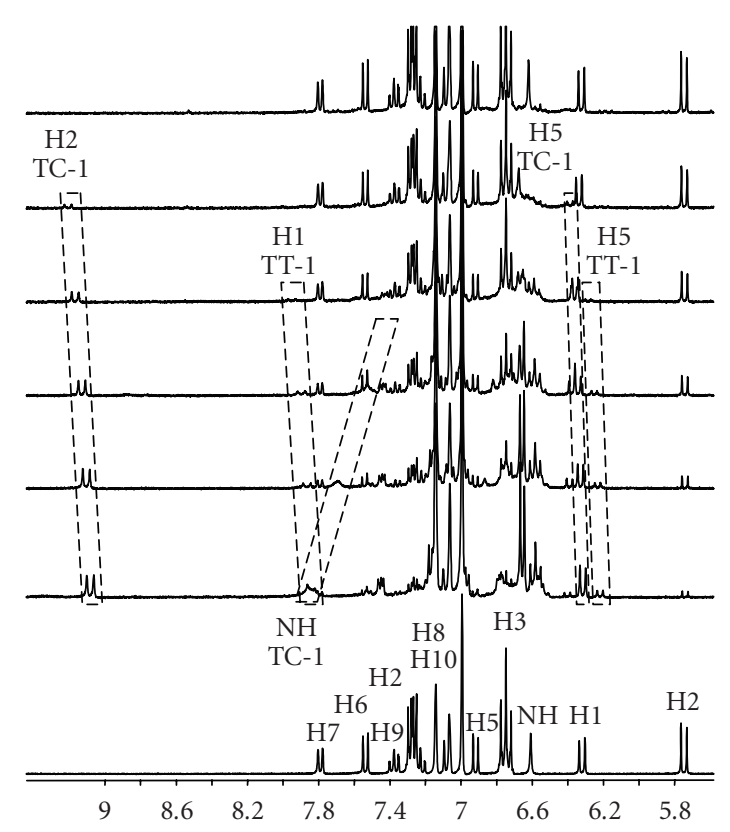

(a)
${ }^{19}$ F NMR

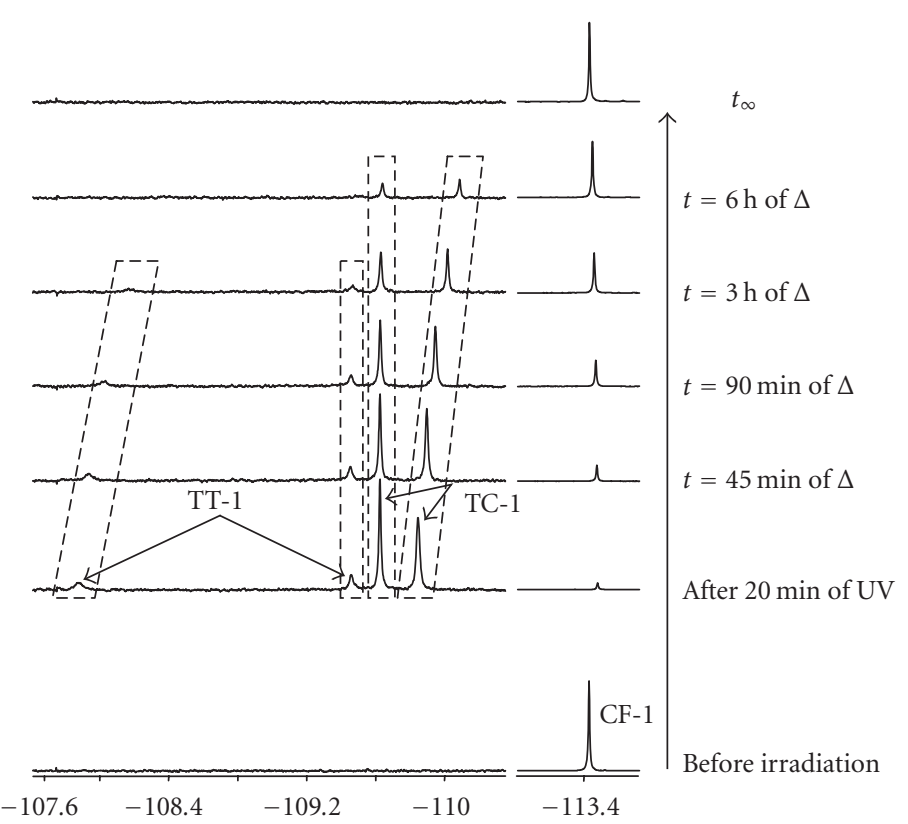

(b)

FIgURE 1: ${ }^{1} \mathrm{H}$ and ${ }^{19} \mathrm{~F}$ NMR spectra of CF-1 in toluene at $223 \mathrm{~K}$.

${ }^{1} \mathrm{H}$ NMR

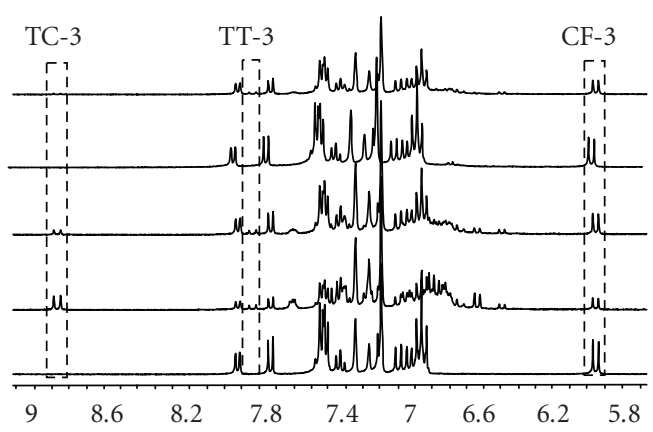

(a)
${ }^{19}$ F NMR

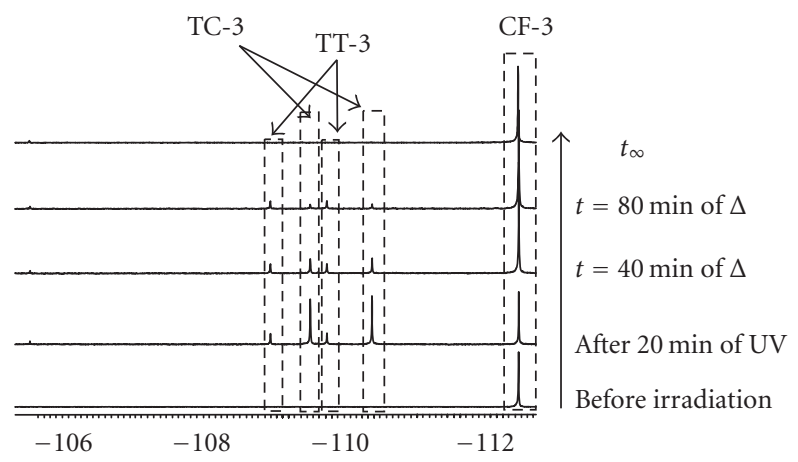

(b)

FIgURE 2: ${ }^{1} \mathrm{H}$ and ${ }^{19} \mathrm{~F}$ NMR spectra of CF-3 in toluene at $223 \mathrm{~K}$.

and $8.2 \mathrm{~Hz}, 8-\mathrm{H}), 7.24(1 \mathrm{H}$, dd $J=1.710-\mathrm{H})$, $7.32\left(4 \mathrm{H}\right.$, dd $J_{2^{\prime}-3^{\prime}}=9.0 \mathrm{~Hz}$ and $J_{2^{\prime}-\mathrm{F}}=5.4 \mathrm{~Hz}$, $\left.2^{\prime}-\mathrm{H}\right), 7.40(1 \mathrm{H}, \mathrm{d} J=8.2 \mathrm{~Hz}, 7-\mathrm{H}), 7.49(1 \mathrm{H}, \mathrm{d}$ $J=8.3 \mathrm{~Hz}, 6-\mathrm{H}) .{ }^{13} \mathrm{C} \mathrm{NMR}(75.47 \mathrm{MHz}$, toluene$\left.\mathrm{d}_{8}\right): 81.3$ (C-3), 107.8 (C-11b), 110.3 (C-5), 111.9 (C10), $115.2\left(\mathrm{C}-3^{\prime}, J_{3^{\prime}-\mathrm{F}} 21,1 \mathrm{~Hz}\right), 118.5(\mathrm{C}-\mathrm{Br}), 120.3$ (C-1) 120.6 (C-7), 121.6 (C-6), 122.3 (C-6b), 122.8 (C-8), 127.0 (C-2), 129.2 (C-2', J $\left.2^{\prime}-\mathrm{F} 8.2 \mathrm{~Hz}\right), 137.0$

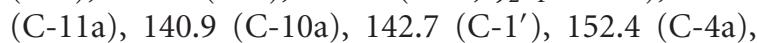
$162.7\left(\mathrm{C}-4^{\prime}, J_{4^{\prime}-\mathrm{F}} 246 \mathrm{~Hz}\right)$. MS (EI, $\left.70 \mathrm{eV}\right): \mathrm{m} / \mathrm{z}(\%)$ : $503\left({ }^{81} \mathrm{BrM}^{+\bullet}, 100\right), 501\left({ }^{79} \mathrm{BrM}^{+\bullet}, 98\right), 423$ (52), 409 (13), 408 (49), 407 (15), 406 (52). Exact mass for $\mathrm{C}_{27} \mathrm{H}_{16} \mathrm{BrF}_{2} \mathrm{NO}$ : 501.0538. Found: 501.0535.

\subsection{Studies by NMR spectroscopy}

${ }^{1} \mathrm{H}$ and ${ }^{19} \mathrm{~F}$ NMR spectra of benzopyrans CF-1 and CF-3 were recorded before and after UV irradiation and during thermal relaxation at different low temperatures (Figures 1 and 2). Two photoproducts with different concentrations were 


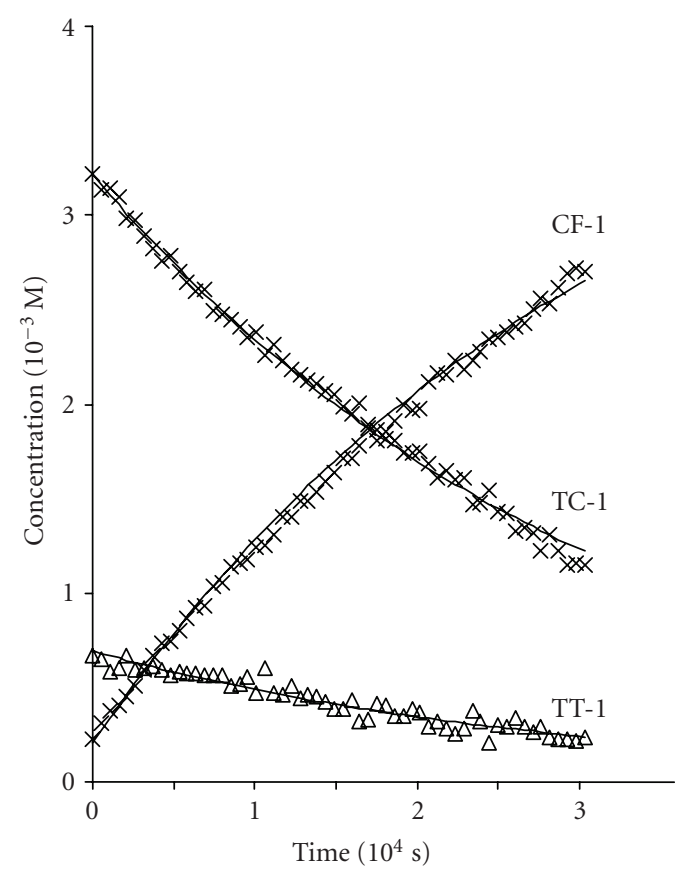

(a)

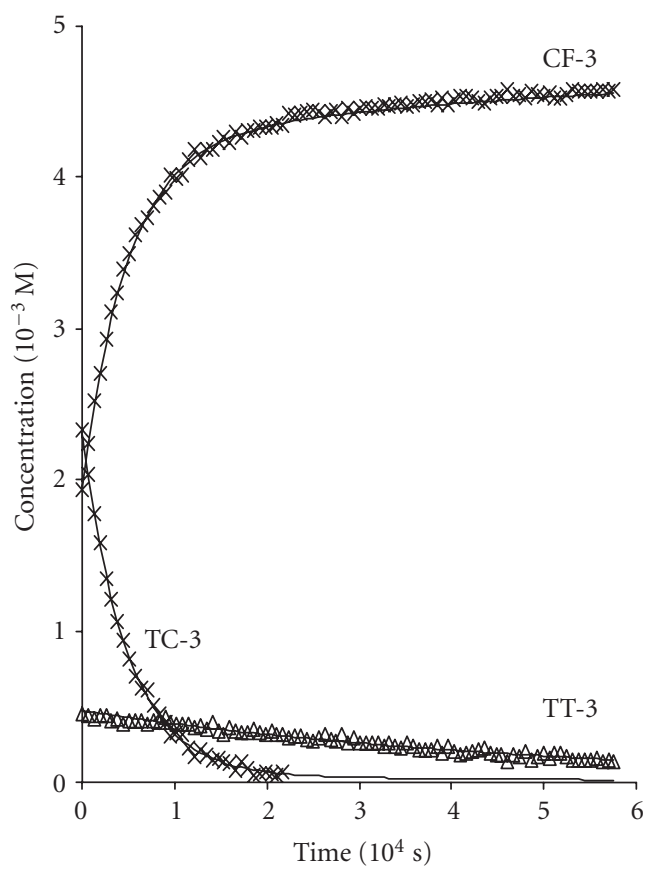

(b)

Figure 3: Time-evolution concentrations of CF-1 and CF-3 after UV irradiation at $223 \mathrm{~K}$.

detected and straightforwardly identified to both transoid isomers of photomerocyanines, TC and TT. They are characterized by two pairs of ${ }^{19} \mathrm{~F}$ resonances due to the $\mathrm{sp}_{2}$ hybridization of carbon C-3 in open form. The typical doublet signal $\left({ }^{3} \mathrm{~J}=12.2 \mathrm{~Hz}\right)$ at $9.0 \mathrm{ppm}$ in ${ }^{1} \mathrm{H}$ NMR spectra, deshielded by $\mathrm{C}=\mathrm{O}$, made it possible to assign the major concentrated product to transoid-cis structure [4]. During the thermal relaxation of CF-1 in toluene solution, a great shift and a pronounced broadening of one fluorine signal in TC and one in TT have been observed. The same effect has also been detected in ${ }^{1} \mathrm{H}$ NMR spectra with a high variation of $\mathrm{NH}$ chemical shift (Figure 1). This phenomenon has not been underlined in acetone solution. This can be explained by intermolecular solute-solute $\mathrm{H}$-bond formation between the attractive $\mathrm{C}=\mathrm{O}$ and the donor $\mathrm{NH}$ favoured in apolar toluene, while acetone leads to solvent-solute interactions.

By measuring the peak-intensities in each of the NMR spectra, the time-evolution curves have been plotted, hence characterising the disappearance of both isomers (Figure 3).

Analysis of the curves indicates that TC follows biexponential decay to return to the initial closed form, while TT presents monoexponential decrease towards TC. The set of kinetic rate constants of this consecutive thermal mechanism (TT $\rightarrow$ TC $\rightarrow \mathrm{CF}$ ) has been used to plot Eyring's lines (Figure 4) and calculate thermodynamic parameters (Table 1). The values calculated for thermodynamic parameters of process from TC to CF are very similar with those generally reported for other chromenes and obtained by NMR spectroscopy as well as by spectrophotometric methods [13$15]$.

\subsection{Studies by UV-visible spectroscopy}

The photochromic behavior of the four compounds was studied in $10^{-4} \mathrm{M}$ toluene solutions under continuous nearUV-visible irradiation. The compounds CF-1 and CF-2 were also investigated in acetone solutions. Maximal absorption wavelengths $\left(\lambda_{\max }\right)$ of the open forms $\left(\lambda_{\mathrm{a}}\right.$ and $\left.\lambda_{\mathrm{b}}\right)$, thermal bleaching rates $\left(\mathrm{k}_{\Delta}\right)$, and colorability, estimated under the experimental conditions by the absorbance of the solution after reaching a photostationary equilibrium $\left(\mathrm{A}_{\mathrm{eq}}\right)$, are the three spectrokinetic parameters evaluated for the characterization of the photochromic compounds. The data are summarized in Table 2.

In all the cases investigated, the kinetics of bleaching follow a biexponential-model characterizing the presence of at least two species. These two species are assigned to both transoid isomers of photomerocyanines, as confirmed by their rate constants of bleaching which are in good agreement with Eyring's plot previously obtained. Consequently, the values $\mathrm{k}_{1}$ and $\mathrm{k}_{2}$ correspond to the thermal rate constants of pathways $\mathrm{TC} \rightarrow \mathrm{CF}$ and $\mathrm{TT} \rightarrow \mathrm{TC}$, respectively.

From the data reported, it appears that the presence of the bromine atom in CF-2 does not really affect the behaviour of non-substituted $\mathrm{CF}-1$. In contrast, the ratio of TC : TT strongly changes if we compare the two compounds having a methyl group at the nitrogen atom. Concerning the maximal wavelengths of the open forms, we observed a bathochromic shift and an extension of the visible spectra which display two bands at ca. $440\left(\lambda_{\mathrm{a}}\right)$ and $580\left(\lambda_{\mathrm{b}}\right) \mathrm{nm}$, due to an increase of the conjugation through the molecule. 


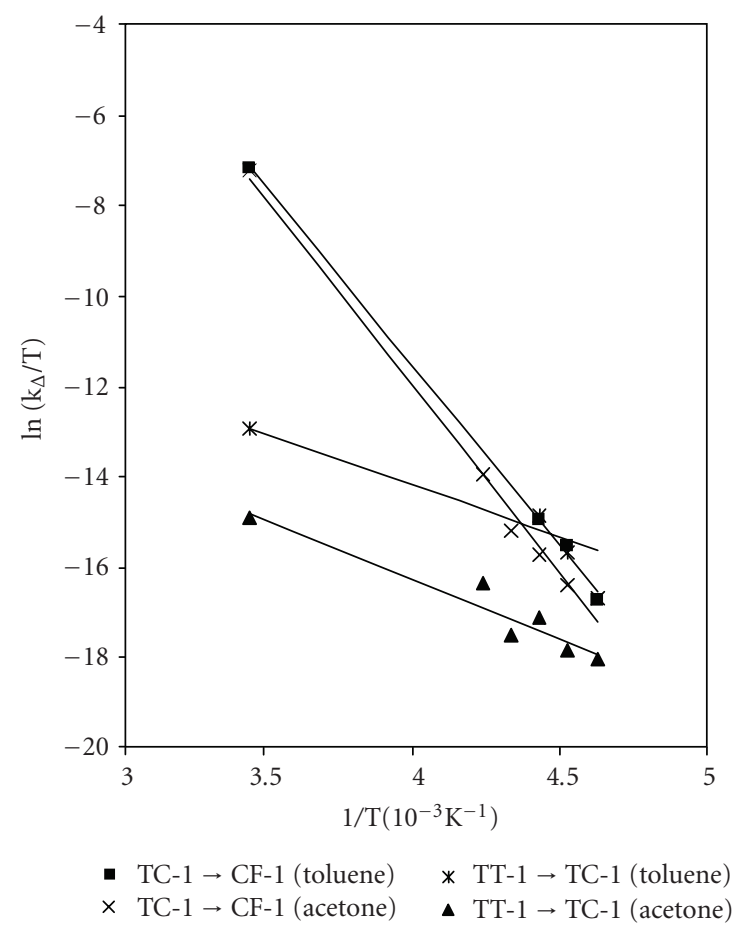

(a)

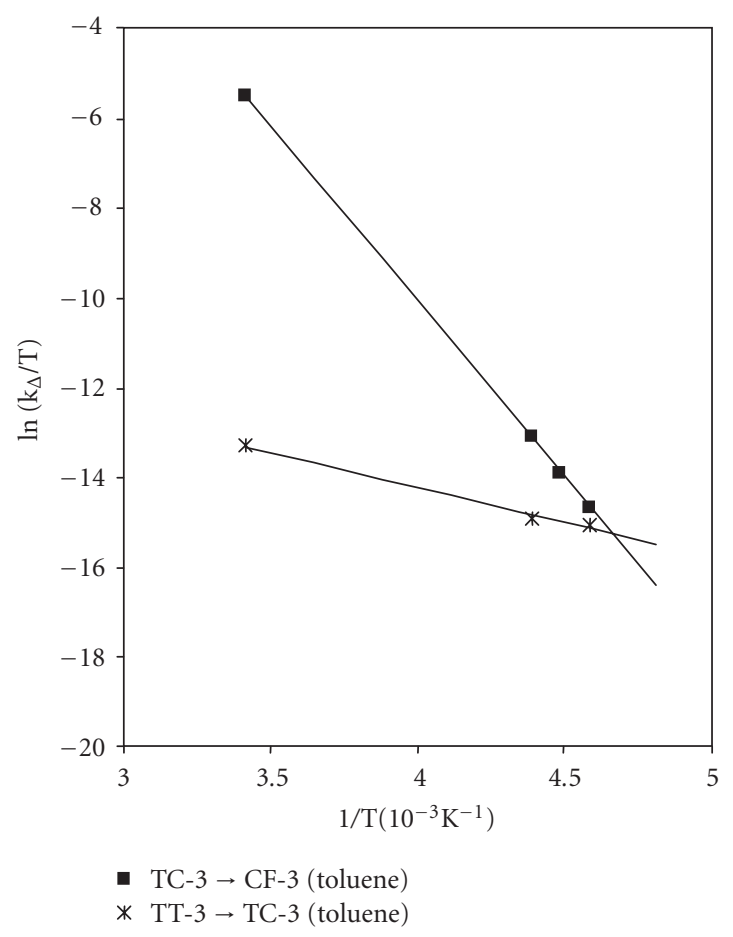

(b)

Figure 4: Eyring's plots of the TT $\rightarrow$ TC $\rightarrow$ CF relaxation processes in CF-1 and CF-3.

TABLE 1: Kinetic rate constants $\left(\mathrm{k}_{\Delta}\right.$ in s $\mathrm{s}^{-1}$ ) and thermodynamic parameters (enthalpy variation $\Delta \mathrm{H}^{\#}$ in $\mathrm{kJ} \cdot \mathrm{mol}^{-1}$ and entropy variation $\Delta \mathrm{S}^{\#}$ in $\mathrm{J} \cdot \mathrm{mol}^{-1} \cdot \mathrm{K}^{-1}$ ) calculated from thermal relaxation recorded by NMR spectroscopy at different low temperatures.

\begin{tabular}{|c|c|c|c|c|c|c|}
\hline \multirow{2}{*}{$\mathrm{T} / \mathrm{K}$} & \multicolumn{2}{|c|}{$\mathrm{k}_{\Delta} \mathrm{TT}-1 \rightarrow \mathrm{TC}-1$} & \multicolumn{2}{|c|}{$\mathrm{k}_{\Delta}$ TC-1 $\rightarrow$ CF-1 } & \multirow{2}{*}{$\begin{array}{c}\mathrm{k}_{\Delta} \mathrm{TT}-3 \rightarrow \mathrm{TC}-3 \\
\text { toluene }\end{array}$} & \multirow{2}{*}{$\begin{array}{c}\mathrm{k}_{\Delta} \mathrm{TC}-3 \rightarrow \mathrm{CF}-3 \\
\text { toluene }\end{array}$} \\
\hline & toluene & acetone & toluene & acetone & & \\
\hline 218 & - & $3.310^{-6}$ & $1.210^{-5}$ & $1.310^{-5}$ & $6.310^{-5}$ & $9.410^{-5}$ \\
\hline 223 & $3.510^{-5}$ & $4.010^{-6}$ & $3.910^{-5}$ & $1.710^{-5}$ & $2.010^{-5}$ & $2.110^{-4}$ \\
\hline 228 & $8.110^{-5}$ & $8.310^{-6}$ & $7.410^{-5}$ & $3.410^{-5}$ & $7.610^{-5}$ & $4.810^{-4}$ \\
\hline 233 & - & $5.810^{-6}$ & - & $5.810^{-5}$ & - & - \\
\hline 238 & - & $1.910^{-5}$ & - & $2.110^{-4}$ & - & - \\
\hline \multirow[t]{2}{*}{$293^{\mathrm{a}}$} & $7.010^{-4}$ & $1.010^{-4}$ & 0.23 & 0.21 & $5.010^{-4}$ & 1.22 \\
\hline & - & - & - & - & - & - \\
\hline$\Delta \mathrm{H}^{\#}$ & 19.2 & 22.2 & 66.8 & 69.6 & 13.0 & 65.1 \\
\hline$\Delta S^{\#}$ & -239.6 & -245.0 & -28.9 & -21.5 & -263.8 & -21.1 \\
\hline
\end{tabular}

aVlues at $293 \mathrm{~K}$ were deduced from UV-visible spectroscopy.

\section{DISCUSSION AND CONCLUSION}

The combined spectrophotometric and NMR study at various temperatures made it possible to obtain values of rate constant in good correlation. The $\mathrm{k}_{\Delta}$ values calculated for the reclosing of TC towards CF-3 and CF- 4 are around five times greater than the corresponding $\mathrm{NH}$ compounds, $\mathrm{CF}-1$ and CF-2, indicating some destabilization of the open forms of the former compounds.

A great difference has also been obtained concerning the reactivity of isomer TT. Indeed, until now, studies of chromenes at low temperature have underlined a high thermal stability of it [4]. Here, we observed its decrease even if experiments were performed at lowest temperatures. One can suggest that the presence of the indole entity in 5, 6 position of benzopyrans leads to steric hindrance, then favouring the destabilization of the two open forms.

Consequently, UV-visible spectroscopy and NMR measurements have pointed out the formation of the two transoid isomers of photomerocyanines, TC and TT. The spectrokinetic parameters and the structural assignment have been obtained, indicating that these two spectroscopies are 
TABLE 2: Maximal absorption wavelengths of the colored forms $\left(\lambda_{\mathrm{a}}\right.$ and $\left.\lambda_{\mathrm{b}}\right)$, colorability $\left(\mathrm{A}_{\mathrm{eq}}\right)$, fading rates $\left(\mathrm{k}_{1}\right.$ and $\left.\mathrm{k}_{2}\right)$ of CF- 1 and CF2 in toluene and acetone and of CF- 3 and CF- 4 in toluene solutions under continuous irradiation $\left(10^{-4} \mathrm{M}\right.$ at $\left.20^{\circ} \mathrm{C}\right)$.

\begin{tabular}{l|cccccc}
\hline & \multicolumn{2}{|c}{ CF-1 } & \multicolumn{2}{c}{ CF-2 } & CF-3 & CF-4 \\
& toluene & acetone & toluene & acetone & toluene & toluene \\
\hline$\lambda_{\mathrm{a}}$ & 451 & 436 & 442 & 432 & 438 & 436 \\
$\lambda_{\mathrm{b}}$ & 590 & 578 & 583 & 578 & 579 & 583 \\
$\mathrm{~A}_{\mathrm{eq}}$ & 0.07 & 0.24 & 0.09 & 0.23 & 0.06 & 0.04 \\
$\mathrm{k}_{1}$ & 0.23 & 0.13 & 0.20 & 0.21 & 1.22 & 0.91 \\
& $(56 \%)$ & $(31 \%)$ & $(48 \%)$ & $(36 \%)$ & $(76 \%)$ & $(27 \%)$ \\
& $710^{-4}$ & $110^{-4}$ & $510^{-4}$ & $510^{-4}$ & $510^{-4}$ & $710^{-4}$ \\
$\mathrm{k}_{2}$ & $(44 \%)$ & $(69 \%)$ & $(52 \%)$ & $(64 \%)$ & $(24 \%)$ & $(73 \%)$ \\
\hline
\end{tabular}

complementary: UV owing to its high sensitivity and timeresolution and NMR owing to its structural identification and the possibility of following the evolution of each form separately.

\section{ACKNOWLEDGMENTS}

The $300 \mathrm{MHz}$ NMR Facilities were funded by the Région Nord-Pas de Calais (France), the Ministère de la Jeunesse, de l'Education Nationale et de la Recherche, and the Fonds Européens de Développement Régional. This work is supported by Calouste Gulbenkian Foundation and CPU/CRUP in the framework "Actions Universitaires Intégrées LusoFrançaises."

\section{REFERENCES}

[1] R. S. Becker and J. Michl, "Photochromism of synthetic and naturally occurring $2 \mathrm{H}$-chromenes and $2 \mathrm{H}$-pyrans," Journal of the American Chemical Society, vol. 88, no. 24, pp. 5931-5933, 1966.

[2] B. Van Gemert, "Benzo and Naphthopyrans (Chromenes)," in Organic Photochromic and Thermochromic Compounds, J. C. Crano and R. J. Guglielmetti, Eds., vol. 1, chapter 3, pp. 111140, Plenum Press, New York, NY, USA, 1999.

[3] J. C. Crano, T. Flood, D. Knowles, A. Kumar, and B. Van Gemert, "Photochromic compounds: chemistry and application in ophthalmic lenses," Pure and Applied Chemistry, vol. 68 , no. 7, pp. 1395-1398, 1996.

[4] S. Delbaere, B. Luccioni-Houze, C. Bochu, Y. Teral, M. Campredon, and G. Vermeersch, "Kinetic and structural studies of the photochromic process of $3 \mathrm{H}$-naphthopyrans by $\mathrm{UV}$ and NMR spectroscopy," Journal of the Chemical Society, Perkin Transactions, vol. 2, pp. 1153-1158, 1998.

[5] F. Ortica, C. Moustrou, J. Berthet, et al., "Comprehensive photokinetic and NMR study of a biphotochromic supermolecule involving two naphthopyrans linked to a central thiophene unit through acetylenic bonds," Photochemistry and Photobiology, vol. 78, no. 6, pp. 558-566, 2003.

[6] F. Ortica, P. Smimmo, G. Favaro, et al., "Effect of oligothiophene substituents on the photophysical and photochromic properties of a naphthopyran," Photochemical \& Photobiological Sciences, vol. 3, pp. 878-885, 2004.
[7] X. Sallenave, S. Delbaere, G. Vermeersch, A. Saleh, and J.-L. Pozzo, "Photoswitch based on remarkably simple naphthopyrans," Tetrahedron Letters, vol. 46, no. 18, pp. 3257-3259, 2005.

[8] M. M. Oliveira, M. A. Salvador, G. Vermeersch, J. Berthet, and S. Delbaere, "Synthesis and photochromic behavior of fluoro $2 \mathrm{H}$-1-benzopyrans containing a carbazole moiety," Molecular Crystals and Liquid Crystals, vol. 431, pp. 473-485, 2005.

[9] M. M. Oliveira, L. M. Carvalho, C. Moustrou, A. Samat, R. Guglielmetti, and A. M. F. Oliveira-Campos, "Synthesis and photochromic behaviour of novel $2 \mathrm{H}$-1-benzopyrans $(=2 \mathrm{H}$ chromenes) derived from carbazololes," Helvetica Chimica Acta, vol. 84, no. 5, pp. 1163-1171, 2001.

[10] C. D. Gabbutt, B. M. Heron, A. C. Instone, et al., "Observations on the synthesis of photochromic naphthopyrans," European Journal of Organic Chemistry, vol. 2003, no. 7, pp. 12201230, 2003.

[11] J. C. Arnall-Culliford, Y. Teral, P. Sgarabotto, M. Campredon, and G. Giusti, "New halogenated diphenyl-2Hbenzo[ $h]$ chromene derivatives: synthesis and optical properties," Journal of Photochemistry and Photobiology A: Chemistry, vol. 159, no. 1, pp. 7-16, 2003.

[12] G. Sartori, G. Casiraghi, L. Bolzoni, and G. Casnati, "General synthesis of $2 \mathrm{H}$-benzo[b]pyrans (chrom-3-enes) from metal phenoxides and .alpha.,.beta.-unsaturated carbonyl compounds," The Journal of Organic Chemistry, vol. 44, no. 5, pp. 803-805, 1979.

[13] G. Ottavi, G. Favaro, and V. Malatesta, "Spectrokinetic study of 2,2-diphenyl-5,6-benzo(2H)chromene: a thermoreversible and photoreversible photochromic system," Journal of Photochemistry and Photobiology A: Chemistry, vol. 115, no. 2, pp. 123-128, 1998.

[14] G. Ottavi, F. Ortica, and G. Favaro, "Photokinetic methods: a mathematical analysis of the rate equations in photochromic systems," International Journal of Chemical Kinetics, vol. 31, no. 4, pp. 303-313, 1999.

[15] J. Hobley and V. Malatesta, "Energy barrier to TTC-TTT isomerisation for the merocyanine of a photochromic spiropyran," Physical Chemistry Chemical Physics, vol. 2, pp. 57-59, 2000 . 


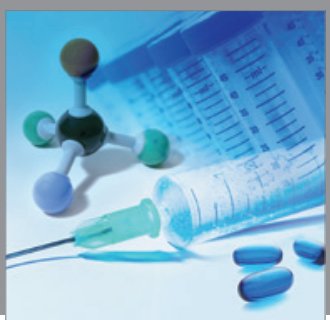

International Journal of

Medicinal Chemistry

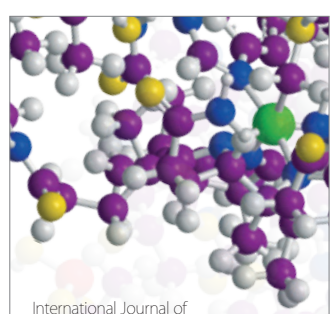

Carbohydrate Chemistry

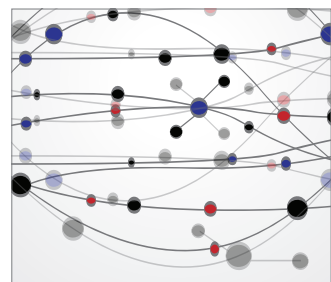

The Scientific World Journal
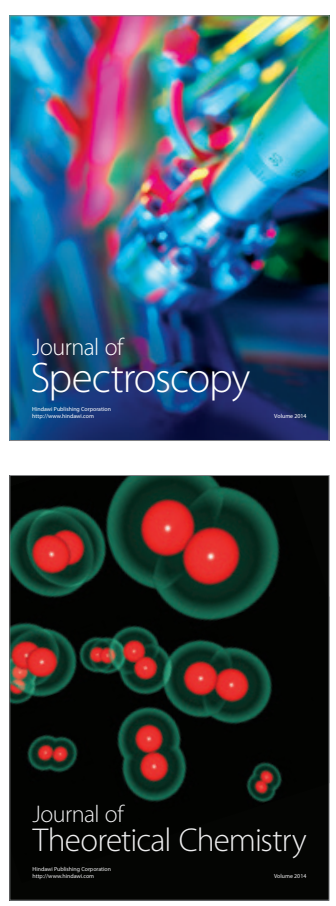
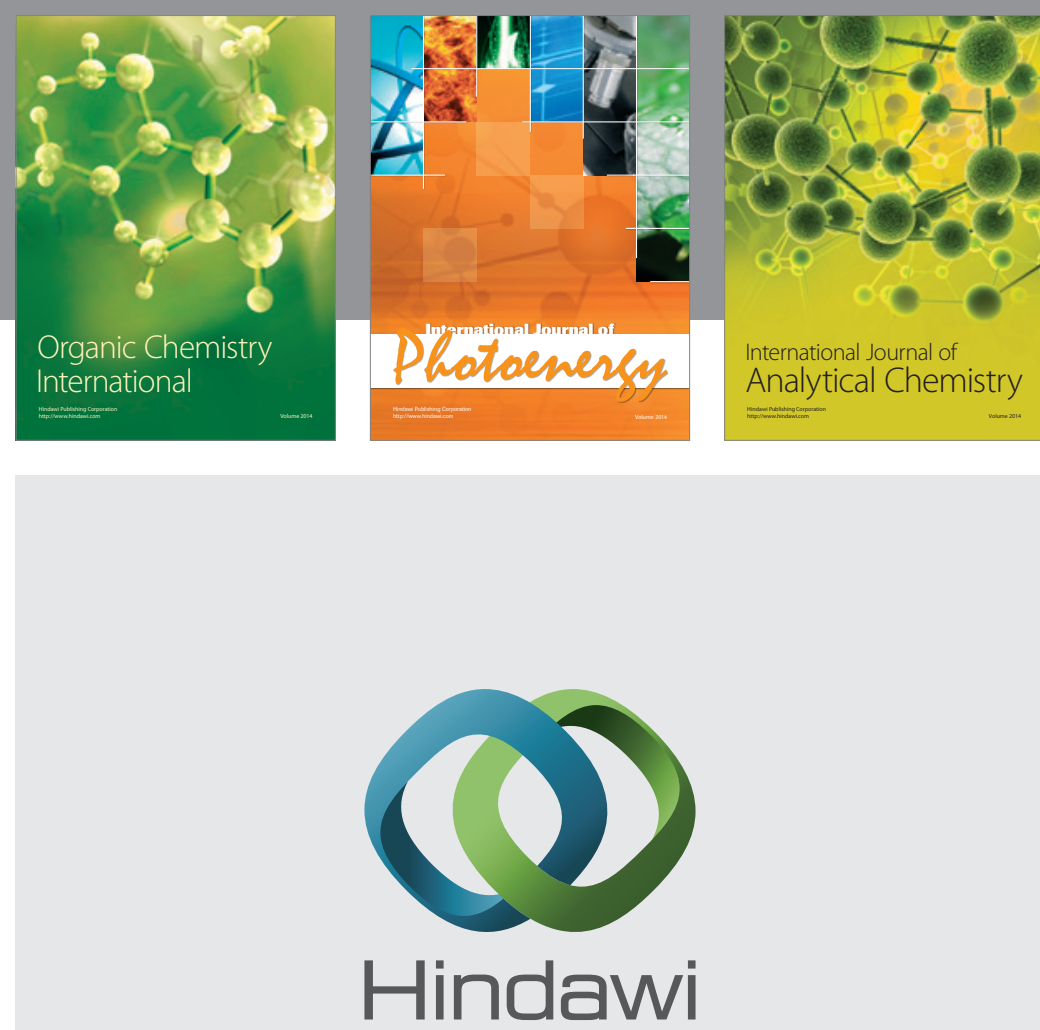

Submit your manuscripts at

http://www.hindawi.com
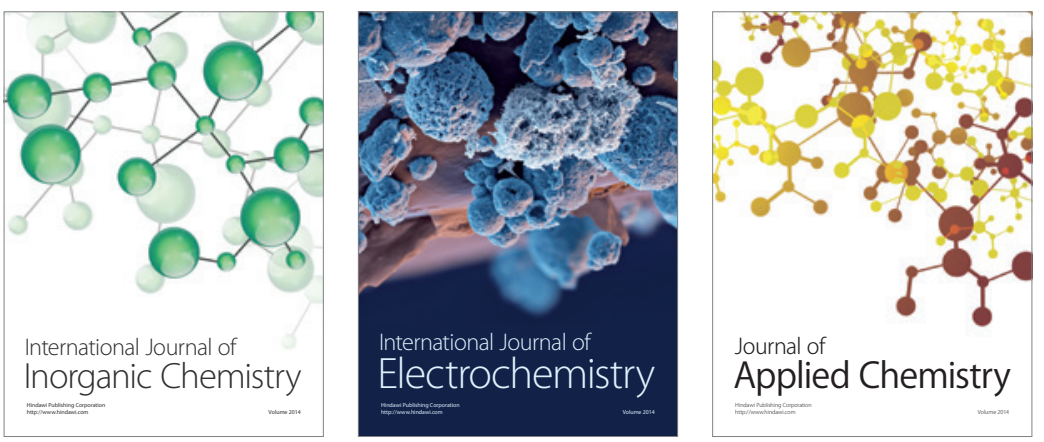

Journal of

Applied Chemistry
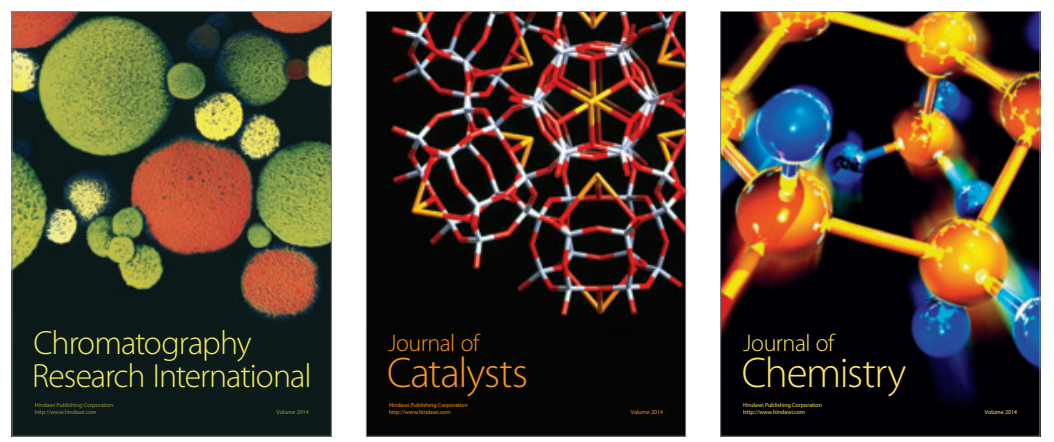
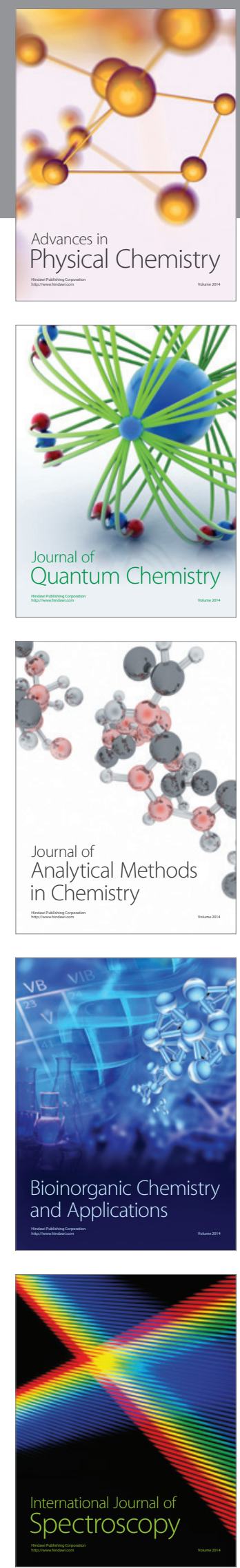